\title{
Multidisciplinary intervention reducing readmissions in medical inpatients: a prospective, non-randomized study
}

This article was published in the following Dove Press journal:

Clinical Interventions in Aging

25 September 2013

Number of times this article has been viewed

\section{Gustav Torisson' \\ Lennart Minthon' \\ Lars Stavenow ${ }^{2}$ \\ Elisabet Londos' \\ 'Clinical Memory Research Unit, Department of Clinical Sciences, Lund University, ${ }^{2}$ Department of Internal Medicine, Skåne University Hospital, Malmö, Sweden}

Background: The purpose of this study was to examine whether a multidisciplinary intervention targeting drug-related problems, cognitive impairment, and discharge miscommunication could reduce readmissions in a general hospital population.

Methods: This prospective, non-randomized intervention study was carried out at the department of general internal medicine at a tertiary university hospital. Two hundred medical inpatients living in the community and aged over 60 years were included. Ninety-nine patients received interventions and 101 received standard care. Control/intervention allocation was determined by geographic selection. Interventions consisted of a comprehensive medication review, improved discharge planning, post-discharge telephone follow-up, and liaison with the patient's general practitioner. The main outcome measures recorded were readmissions and hospital nights 12 months after discharge. Separate analyses were made for 12-month survivors and from an intention-to-treat perspective. Comparative analyses were made between groups as well as within groups over time.

Results: After 12 months, survivors in the control group had 125 readmissions in total, compared with 58 in the intervention group (Mann-Whitney $U$ test, $P=0.02$ ). For hospital nights, the numbers were 1,228 and 492, respectively $(P=0.009)$. Yearly admissions had increased from the previous year in the control group from 77 to 125 (Wilcoxon signed-rank test, $P=0.002$ ) and decreased from 75 to 58 in the intervention group $(P=0.25)$. From the intention-to-treat perspective, the same general pattern was observed but was not significant $(1,827$ versus 1,008 hospital nights, Mann-Whitney test, $P=0.054$ ).

Conclusion: A multidisciplinary approach, targeting several different areas, could substantially lower readmissions and hospital costs in a non-terminal general hospital population.

Keywords: medical inpatients, hospital readmissions, intervention, drug-related problems, cognitive impairment, hospital discharge

\section{Introduction}

Hospital readmissions are common in older inpatients, with one fifth being readmitted within 30 days and $60 \%$ within a year, and unplanned readmissions accounting for $90 \% .^{1,2}$ This issue is becoming increasingly important because many countries have aging populations and are reducing hospital bed capacity. ${ }^{3,4}$

Previous studies propose that a proportion of these readmissions are avoidable. ${ }^{5-9}$ Numerous interventions have succeeded by targeting a specific condition, primarily heart failure, which is a known risk factor for readmissions. ${ }^{1,2,10}$ Another condition, highly prevalent in medical inpatients, but with fewer successful interventions, is cognitive impairment. ${ }^{11-15}$ The methods applied in these studies include improved discharge practices and hospital-based follow-up after discharge. ${ }^{16-19}$ However, a high-
Correspondence: Gustav Torisson

Clinical Memory Research Unit, Department of Clinical Sciences, Malmö, Lund University, Simrisbanvägen I4,

SE-205 02 Malmö, Sweden

Tel +4640335036

Fax +46 40335657

Email gustav.torisson@med.lu.se 
quality intervention study that reduced the incidence of delirium demonstrated disappointing results regarding readmissions. ${ }^{20,21}$ Apart from specific conditions, more general approaches have also been applied. Adverse drug reactions have been the focus of interventions succeeding in reducing hospital readmissions. ${ }^{22,23}$ Another area suggested for intervention is communication gaps in the transition between caregivers. $^{24,25}$

We designed a multidisciplinary intervention applying methods previously shown to be effective, such as discharge improvement and medication overviews, combined with approaches targeting cognitive impairment and miscommunication. Our aim was to apply this intervention in a broad general hospital population and evaluate it regarding readmissions through a prospective approach.

\section{Materials and methods Setting}

The city of Malmö in southern Sweden (population 300,000) consists of ten boroughs. The demographics of the boroughs differ and a majority of the city's elderly population lives in two boroughs, from here on called borough A and B. Every borough has a social services department, managing community care services, and 2-3 primary health care centers. Inpatient care in Malmö is provided by the Skåne University Hospital, a 700-bed tertiary hospital. The department of general internal medicine at this hospital contains four wards with 100 beds in total. The four wards have a similar general medical orientation, treating primarily elderly patients with multiple disorders.

Before discharge, hospital staff initiate the coordination of post-discharge services, including community care and primary care follow-up. First, hospital staff obtain information from community care, patients, and relatives to determine if a significant loss of function has occurred before or during hospitalization. If additional support at home is considered desirable or necessary, a multidisciplinary conference is held at the ward, assessing specific needs. The handover of medical responsibility to the general practitioner is managed through a discharge summary (containing main diagnosis, current medication list, follow-up arrangements) sent to the general practitioner on the day of discharge.

\section{Patients}

\section{Control versus intervention}

Patients living in borough A and B formed the intervention group, with patients from the eight other boroughs as controls, using convenience sampling. Data collection commenced in November 2009, starting with the control group. When 101 controls were included, data collection began in the intervention phase in February 2010 (Figure 1).

\section{Ineligibility and exclusion criteria}

Four ineligibility criteria were applied, ie, age under 60 years, living outside Malmö, living in a nursing home, and prior enrollment (a patient could only be included once).

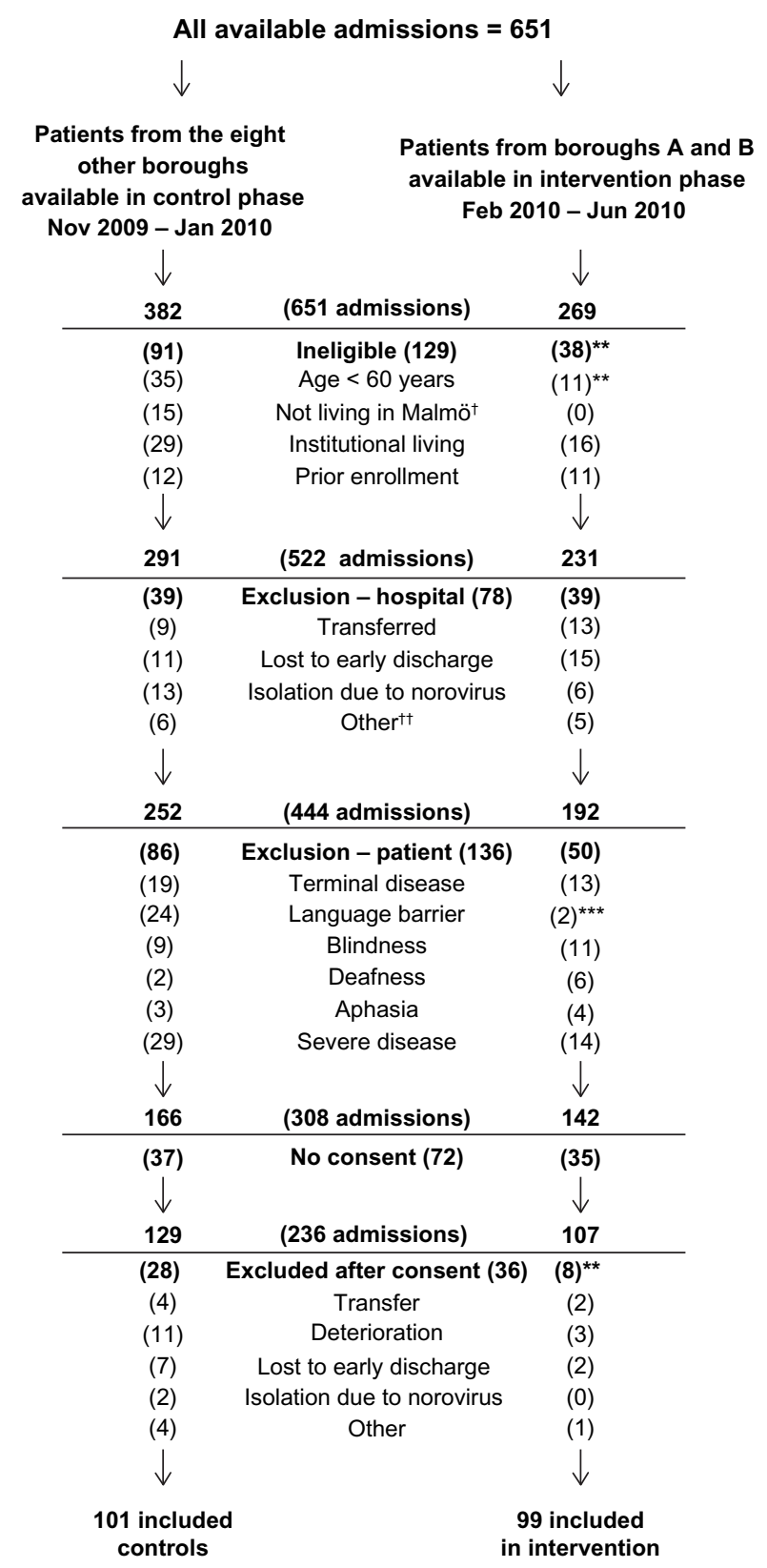

Figure I Patient flow and exclusion criteria.

Notes: ${ }^{\dagger}$ Not applicable since address was a criteria for availability in the intervention

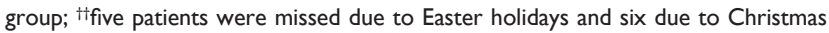
holidays; $* * P \leq 0.01$, $* * * P \leq 0.001$. 
Exclusion criteria included aspects related to time restraints and the hospital (transfer to another department, lost to early discharge, isolation due to communicable disease). Patient-related factors that obstructed cognitive tests or made these inappropriate (terminal disease, language barrier, blindness/deafness/aphasia, or severe disease with inability to communicate, eg, because of altered consciousness) also resulted in exclusion.

\section{Ethics statement}

The study was performed according to the Declaration of Helsinki. All included patients gave their written informed consent and the study protocol was approved by the regional ethics committee of Lund University (2009/662).

\section{Baseline measurements}

All baseline measurements were conducted by study staff in a private environment at the wards during office hours. The study staff consisted of one project manager/physician (GT) and three experienced research assistants (one registered nurse and two occupational therapists).

\section{Demographics and comorbidity}

Patients were interviewed about living arrangements, current community care utilization, and educational level. All comorbidities recorded in the electronic medical record during the current and three preceding admissions were noted. Cumulative comorbidity was determined using the Charlson comorbidity index, assigning different weights from 1 to 6 for different disorders, eg, coronary heart disease is weighted 1 and tumor with metastasis $6{ }^{26}$

\section{Cognitive tests and activities of daily living}

We applied the Mini-Mental State Examination, scored from 0 to 30 , and the Clock-Drawing Test, scored from 0 to $5 .{ }^{27,28}$ In both tests, low scores indicate cognitive impairment. Ability to perform activities of daily living (ADL) was quantified using the ADL subset of the GBS (Gottfries-Bråne-Steen) scale. ${ }^{29}$ The GBS-ADL scale contains six items (dressing, eating, physical activity, spontaneous activity, personal hygiene, continence), each scored from 0 to 6 for a total score of 0 to 36 , with higher scores signifying ADL impairment.

\section{Preceding health care utilization}

For each patient, emergency department visits, hospital admissions, and hospital nights for the preceding 12 months were extracted from the hospital's electronic medical record.
The number of general practitioner visits in the preceding 6 months was determined using the regional health care registry.

\section{Interventions}

\section{Pharmacist intervention}

A clinical pharmacist performed a medication review, using a method called the Lund Integrated Medicines Management model.$^{30}$ First, the patient's most accurate list of medications was established from structured interviews, records from primary care, community care, and the National Pharmacy Register. ${ }^{31}$ The list was compared with the current list at the hospital. Unintentional discrepancies, known as medication errors, were noted and classified into five groups, ie, omission of drug, erroneous addition of drug, dose too high, dose too low, and wrong dosage form (eg, sustained release). ${ }^{32}$

Moreover, throughout the hospitalization, the pharmacist identified and monitored drug-related problems using interviews, hospital records, laboratory values, and physiologic data. ${ }^{33}$ Drug-related problems were classified as unknown indication for treatment, dose not adapted to renal/liver function, inappropriate drug in the elderly (according to hospital policy, based on the recommendations of the National Board of Health and Welfare), adverse drug reaction, untreated or not optimally treated indication, transferring error at discharge, non-adherence, and drug handling (eg, problems with swallowing or crushing). ${ }^{34}$ Based on medication errors and drug-related problems, a recommendation was developed and delivered to the ward physician, who made all decisions regarding medications.

\section{Discharge conference}

If a discharge conference was required, the social services were informed beforehand by study staff regarding cognitive test results. Thus, everyone was aware of any cognitive deficits in advance and could prepare accordingly for the conference. Study staff attended all conferences, conveying cognitive and ADL impairment in a standardized way, based on the MiniMental State Examination, Clock-Drawing Test, and GBS-ADL scales. Numbers of discharge conferences, discharge destinations, and length of stay were recorded for evaluation.

\section{Telephone follow-up}

The registered nurse was assigned the role of communication nurse. The communication nurse met with all patients and relatives at the hospital, providing them with a booklet containing contact information, and encouraged them to call in case of any worries after discharge. The communication nurse called all 
discharged patients in their homes within one week, asking the set of questions found in Table S1. If a problem had occurred, the communication nurse could provide counseling, book an appointment at the community health center, or initiate a home visit from social services, usually on the same day. Numbers of calls and minutes on the phone were noted.

\section{General practitioner liaison}

The ordinary discharge summary sent to general practitioners was accompanied by a separate document containing cognitive test results and a recommendation on how to proceed with investigations. The recommendation was based on an algorithm using Mini-Mental State Examination, Clock-Drawing Test, and age (see Table S2). The general practitioners had the opportunity to discuss the results and recommendations with the study physician. After 12 months, the number of patients who had obtained a registered diagnosis of dementia were recorded.

\section{Standard care in control group}

In the control group, all baseline measurements were performed but none of the interventions. Regular staff were informed of cognitive test results verbally and through the electronic medical record. Apart from this, the control group received standard care.

\section{Health care utilization after 12 months}

Emergency department visits, readmissions, and hospital nights were recorded after 12 months, using the hospitals electronic medical record. All overnight readmissions were recorded, regardless of department and presenting complaint, except for hospice admissions. General practitioner visits were noted from the PASIS regional electronic registry. All data regarding health care utilization was analyzed twice, in a random sequence by two persons blinded to group allocation.

\section{Statistical analysis}

Sample size estimation was based on a comparable intervention study with a mean difference of 2.6 hospital days between control and intervention groups. ${ }^{18}$ The standard deviation for readmission was 6.6 days. To detect a similar difference with a statistical power of 0.8 and $\alpha$ of $0.05,2 \times(2.8 \times 6.6 / 2.6)^{2}=101$ patients were needed in each group. For baseline measurements, $t$-tests, MannWhitney $U$ tests, and Chi-square tests were used where appropriate.

The primary outcome measure was health care utilization after 12 months. This was analyzed following the intention- to-treat principle and for 12-month survivors, separately. To estimate hospital costs, we applied the costs of the Swedish Association of Local Authorities and Regions, equivalent to $281 €$ per emergency department visit and $651 €$ per hospital night, using an exchange rate of 8.614 Swedish crowns to $1 €$, as of February 4, 2013. ${ }^{35}$ Health care utilization was compared between the groups using the Mann-Whitney $U$ test.

Due to the non-randomized design, health care utilization after 12 months was compared with that in the 12 months preceding the index hospitalization. This analysis was performed using the matched-pairs Wilcoxon signed-rank test for the control and intervention groups separately. Thus, it was possible to decide whether health care utilization had increased, decreased, or remained constant over time. To obtain equivalent time periods only, 12-month survivors were included in this analysis.

In all statistical tests, a two-sided $P$-value of $<0.05$ was considered to be statistically significant. The statistical procedures were performed using Statistical Package for the Social Sciences version 19.0 software (SPSS Inc, Chicago, IL, USA).

\section{Results}

\section{Patients}

In total, 594 unique patients were admitted 651 times, with 382 admissions in the control phase and 269 in the intervention phase (Figure 1). The patient was ineligible in 129 admissions, excluded for hospital-related reasons in 78, excluded for patient-related factors in 136, lack of consent in 72 , and was excluded due to events occurring between giving consent and starting the baseline measurements in 36 cases (Figure 1). There were no differences in age between these categories by analysis of variance $[F(5,599)=1.07$, $P=0.38]$. The age group $<60$ years was not included in this analysis. There were no differences in gender between the groups $\left[\chi^{2}(5, \mathrm{n}=651)=7.38, P=0.19\right]$.

\section{Baseline measurements}

Age and education level were higher in the intervention group. Combined comorbidity and cognitive tests did not differ between groups. On the GBS-ADL, there were no differences in the separate items (data not shown) or in total score. Previous health care utilization did not differ between the groups regarding hospitalizations, but there was a trend toward the control group having had more emergency department visits and fewer general practitioner visits (Table 1).

The patients were distributed across the four wards in the department as follows: ward A (control/intervention) 
Table I Baseline measurements

\begin{tabular}{llll}
\hline & Intervention & Controls & P-value \\
\hline Age, years & $84.6(7.3)$ & $82.3(8.7)$ & $0.04^{*}$ \\
Female gender & $64 \%$ & $66 \%$ & 0.77 \\
Living alone & $62 \%$ & $72 \%$ & 0.13 \\
Home care & $57 \%$ & $58 \%$ & 0.89 \\
Education $>9$ years & $56 \%$ & $37 \%$ & $0.0 I^{*}$ \\
Neurocognitive disorder & $11 \%$ & $4 \%$ & 0.06 \\
Coronary heart disease & $34 \%$ & $33 \%$ & 0.88 \\
Arrhythmia & $38 \%$ & $32 \%$ & 0.37 \\
Heart failure & $31 \%$ & $25 \%$ & 0.35 \\
Hypertension & $50 \%$ & $48 \%$ & 0.89 \\
COPD & $16 \%$ & $23 \%$ & 0.29 \\
Gastrointestinal disease & $19 \%$ & $15 \%$ & 0.46 \\
Stroke & $23 \%$ & $17 \%$ & 0.29 \\
Diabetes & $15 \%$ & $31 \%$ & $0.01 *$ \\
Cancer, non-skin & $30 \%$ & $26 \%$ & 0.53 \\
CCI & $2.4(I .4)$ & $2.1(1.6)$ & 0.27 \\
MMSE & $23.0(4.7)$ & $22.7(3.7)$ & 0.66 \\
CDT & $3.3(1.3)$ & $3.5(1.2)$ & 0.33 \\
GBS-ADL & $6.6(5.3)$ & $6.9(6.0)$ & 0.71 \\
GP visits & $1.9(1.7)$ & $1.6(2.3)$ & 0.08 \\
Emergency department visits & $1.3(I .6)$ & $2.4(3.7)$ & 0.08 \\
Admissions & $1.1(1.5)$ & $1.4(2.0)$ & 0.61 \\
Hospital nights & $8.0(12.9)$ & $11.3(17.0)$ & 0.31 \\
\hline Notes All & & & $3 \%$ \\
\hline
\end{tabular}

Notes: All data are mean (standard deviation) or percentages. General practitioner visits were recorded for the preceding 6 months, emergency department visits, admissions and hospital nights for 12 months. $* P \leq 0.05$.

Abbreviations: COPD, chronic obstructive pulmonary disease; $\mathrm{CCl}$, Charlson comorbidity index; MMSE, Mini-Mental State Examination, scored from 0 (worst) to 30 (best); CDT, Clock-Drawing Test, scored from 0 (worst) to 5 (best); GBS-ADL, activities of daily living subset of the GBS scale, scored from 0 (best) to 36 (worst); GBS, Gottfries-Bråne-Steen.

20/22, ward B 42/36, ward C 34/28, and ward D 4/14, with a significant difference for the latter $\left[\chi^{2}(1, n=200)=6.63\right.$, $P=0.01]$. The entire ward $\mathrm{D}$ was put in isolation for a substantial time due to a Norovirus epidemic.

\section{Interventions}

The distributions of medication errors and drug-related problems are shown in Table 2. The pharmacist gave recommendations to the ward physician for 73 of 99 patients, which were followed by the physician completely in 53, partially in 16 , and not at all in four.

There was no difference between groups in number of discharge conferences $\left[\chi^{2}(1, \mathrm{n}=200)=0.002, P=1.0\right]$. Neither were there any differences regarding length of stay $[\mathrm{U}(200)=4883, \mathrm{z}=0.16, P=0.87]$ or discharge destination $\left[\chi^{2}(1, \mathrm{n}=196)=0.060, P=0.56\right.$, see Table 2$]$.

The communication nurse reached 65 of 81 patients discharged to their homes, of whom 38 had experienced problems after discharge. For 31 patients, an action was taken by the communication nurse (Table 2). Only four of 38 patients with a problem actively contacted the communication nurse. Ten patients
Table 2 Details of interventions

\begin{tabular}{|c|c|c|}
\hline & Intervention & Controls \\
\hline \multicolumn{3}{|l|}{ Medication overview } \\
\hline Any medication error & $52 \%$ & - \\
\hline Median (range) & I (0-6) & - \\
\hline Medication errors, total & 111 & - \\
\hline Omission of drug & 70 & - \\
\hline Addition of drug & 15 & - \\
\hline Dose too high & II & - \\
\hline Dose too low & 9 & - \\
\hline Wrong dosage form & 6 & - \\
\hline Any drug-related problem & $65 \%$ & - \\
\hline Median (range) & I (0-7) & - \\
\hline Drug-related problems, total number & 145 & - \\
\hline Unclear indication & 43 & - \\
\hline $\begin{array}{l}\text { Dose not adapted to renal/liver } \\
\text { function }\end{array}$ & 29 & - \\
\hline Inappropriate in elderly & 23 & - \\
\hline Adverse reaction & 21 & - \\
\hline Untreated indication & 19 & - \\
\hline Transferring error & 8 & - \\
\hline Non-adherence & 5 & - \\
\hline Drug handling & 3 & - \\
\hline \multicolumn{3}{|l|}{ Discharge conference } \\
\hline Discharge conference held & $69 \%$ & $70 \%$ \\
\hline Discharged to nursing home & $18 \%$ & $14 \%$ \\
\hline Length of stay, days, median (range) & $9(3-4 I)$ & $9(2-29)$ \\
\hline \multicolumn{3}{|l|}{ Telephone follow-up } \\
\hline Action taken, total & 31 & - \\
\hline Medication counseling & 5 & - \\
\hline Other counseling & 6 & - \\
\hline Appointment made & 14 & - \\
\hline Complementing prescriptions & 6 & - \\
\hline \multicolumn{3}{|l|}{ GP liaison } \\
\hline Recommendation sent & $100 \%$ & - \\
\hline No follow-up needed & $14 \%$ & - \\
\hline New cognitive tests promptly & $38 \%$ & - \\
\hline New tests in 6 months & $30 \%$ & - \\
\hline New tests in 12 months & $18 \%$ & - \\
\hline
\end{tabular}

Note: Data are presented as percentages, numbers, or median (range). Abbreviation: GP, general practitioner.

were called more than once for a total of 78 calls. The time spent on the phone by the communication nurse was 604 minutes with a median of 5 (range 0-80) minutes per call.

The recommendations based on the algorithm in Appendix 2 and sent to general practitioners on the day of discharge are shown in Table 2. After 12 months, 23 patients in the intervention group had obtained a diagnosis of dementia compared with 12 in the control group $\left[\chi^{2}(1, n=200)=4.46\right.$, $P=0.04]$.

\section{Health care utilization after 12 months}

After 12 months, 63 patients were deceased (31 in the control group and 32 in the intervention group). The median (interquartile range) survival was 96 (32-222) days. 
In intention-to-treat analysis, the control group had more emergency department visits, readmissions, and hospital nights as well as higher hospital costs than the intervention group but the difference was not statistically significant, with a trend for more hospital nights in the control group $(P=0.054)$. For the 12 -month survivors $(n=137)$, the differences were statistically significant regarding readmissions, hospital nights, and hospital costs (Table 3).

Over time, the yearly admissions in the control group increased from 77 to 125 (Wilcoxon signed-rank test, 36 positive differences, 13 negative, 21 ties, $\mathrm{z}=3.16$, $P=0.002$ ). In the intervention group, the yearly admissions decreased insignificantly from 75 to 58 (Wilcoxon signed-rank test, 18 positive differences, 25 negative, 24 ties, $\mathrm{z}=1.14, P=0.25)$. A similar pattern was seen for hospital nights (Figure 2).

\section{Discussion}

In this prospective study in medical inpatients, an intervention group had substantially fewer hospital readmissions than a group receiving standard care. After 1 year, survivors of the intervention group had spent 492 nights in hospital compared with 1228 in the control group. In the year preceding the intervention, the same groups had had 501 and 549 hospital nights, respectively. However, the difference between groups was statistically significant for 12-month survivors only. From an intention-to-treat perspective, there was a substantial arithmetic difference, albeit with a lower significance level $(P=0.054)$. One reason for this might be that some patients in the intervention group did not have time to benefit fully from the interventions, eg, those who passed away shortly after discharge. Another possible explanation is that health care utilization increases dramatically during the last months of life and interventions in the last year are seldom effective. ${ }^{36,37}$

The difference in readmissions corresponds to a substantial economic impact. For 12-month survivors, the hospital costs of the intervention group were $337,000 €$ compared with $831,000 €$ in the control group, for a difference of $494,000 €$. In comparison, the budget of the project as a whole, including planning and collection of data in both groups, was approximately $150,000 €$. Although being indirect ways of assessment, the number of general practitioner visits, discharge planning, and discharge destinations gave no indication toward increased costs elsewhere. The intervention provided other interesting results as well. Fifty-two percent of patients had medication errors on admission and $65 \%$ had actual or potential drug-related problems, in line with other research in similar settings. ${ }^{32}$ Given the high occurrence of cognitive impairment, the need for structured

Table 3 Health care utilization after 12 months from $(\mathbf{A})$ intention-to-treat perspective $(n=200)$ and $(\mathbf{B})$ for survivors $(n=137$ with 67 in the intervention group and 70 in the control group)

\begin{tabular}{|c|c|c|c|c|c|}
\hline & Intervention & Control & Difference & Test statistic & $P$-value \\
\hline \multicolumn{6}{|l|}{ (A) Intention-to-treat } \\
\hline GP visits, total & 335 & 316 & -19 & & \\
\hline Mean (SD) & $3.4(3.3)$ & $3.4(3.2)$ & & $U(200)=5440, z=1.49$ & 0.14 \\
\hline ED visits, total & 133 & 219 & 84 & & \\
\hline Mean (SD) & $\mathrm{I} .4(\mathrm{I} .7)$ & $2.2(3.8)$ & & $U(200)=4389, z=1.20$ & 0.23 \\
\hline Readmissions, total & 104 & 171 & 66 & & \\
\hline Mean (SD) & I.I (I.3) & $\mathrm{I} .7(2.3)$ & & $U(200)=4183, z=1.75$ & 0.08 \\
\hline Hospital nights, total & 1008 & 1827 & 819 & & \\
\hline Mean (SD) & $10.3(16.0)$ & I8.5 (29.6) & & $U(200)=4105, z=1.92$ & 0.054 \\
\hline Hospital costs, $\times 1000 €$ & 681 & 1227 & 546 & & \\
\hline Mean (SD) & $7.0(10.6)$ & $15.7(19.6)$ & & $U(200)=4134, z=1.82$ & 0.07 \\
\hline \multicolumn{6}{|l|}{ (B) I2-month survivors } \\
\hline GP visits, total & 271 & 245 & -26 & & \\
\hline Mean (SD) & $4.0(3.6)$ & $3.5(4.6)$ & & $U(I 37)=2786, z=1.92$ & 0.06 \\
\hline ED visits, total & 83 & 170 & 87 & & \\
\hline Mean (SD) & $\mathrm{I} .2(\mathrm{I} .7)$ & $2.4(4.4)$ & & $U(137)=2013, z=1.49$ & 0.14 \\
\hline Readmissions, total & 58 & 125 & 67 & & \\
\hline Mean (SD) & $0.9(1.2)$ & I.8 (2.5) & & $U(137)=|840, z=2.4|$ & 0.02 \\
\hline Hospital nights, total & 492 & 1228 & 736 & & \\
\hline Mean (SD) & $7.3(15.4)$ & $17.5(29.7)$ & & $U(\mid 37)=|770, z=2.6|$ & 0.009 \\
\hline Hospital costs, $\times 1000 €$ & 337 & 831 & 494 & & \\
\hline Mean (SD) & $4.9(10.1)$ & II.8 (19.6) & & $U(137)=1776, z=2.52$ & 0.01 \\
\hline
\end{tabular}

Abbreviations: GP, general practitioner; ED, emergency department; SD, standard deviation. 
A

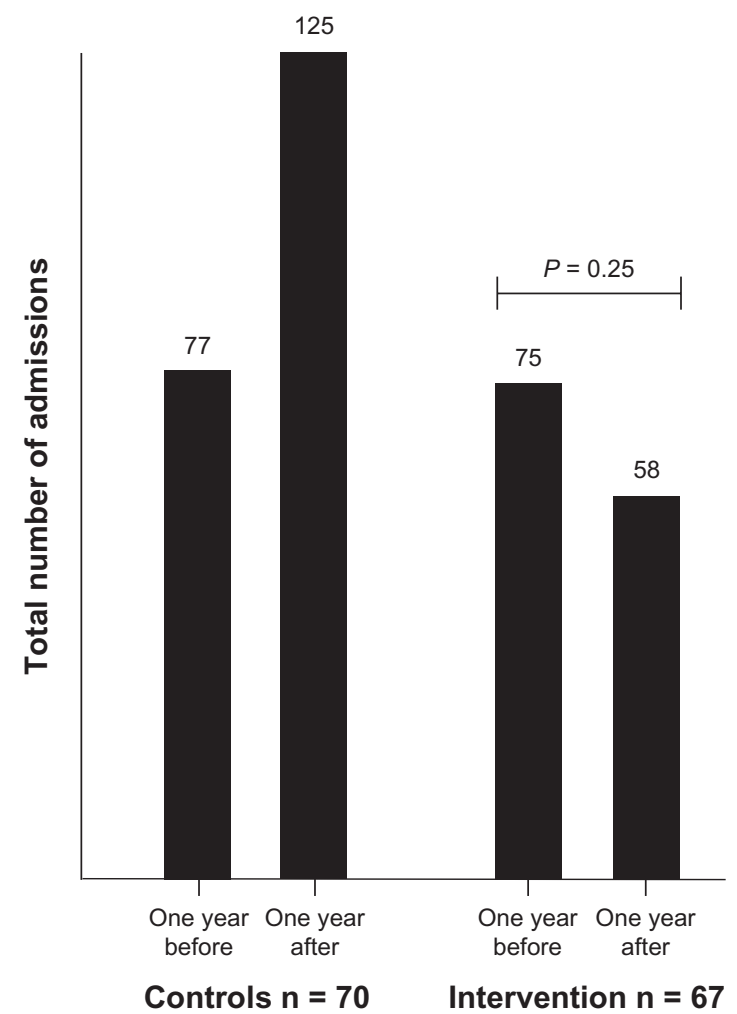

B

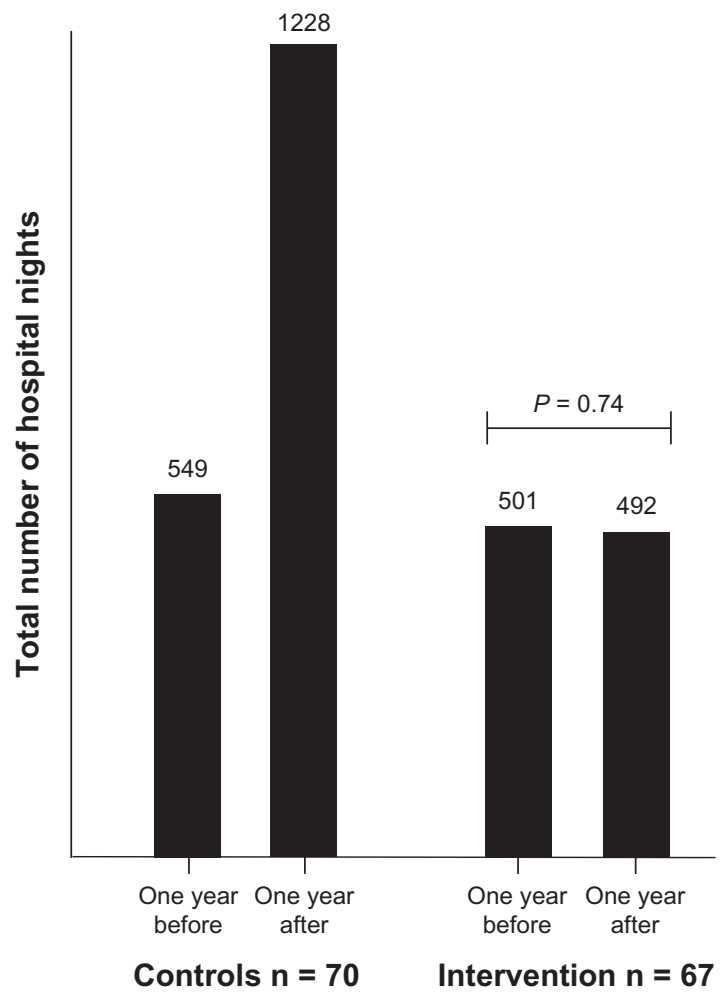

Figure 2 Pairwise comparisons within the two groups regarding readmissions (A) and hospital nights (B).

Notes: All comparisons are made for the year preceding the index hospitalization versus the year after the index hospitalization. $P$-values represent matched-pairs Wilcoxon signed-rank test.

medication reviews in this population is probably extensive. Although the communication nurse had met with all patients and relatives, supplied them with a direct way of contact, and encouraged them to call, only four of 38 with a post-discharge problem did so. This requires a more proactive approach of reaching out to patients rather than merely instructing them to contact the health care system or local authorities if problems arise.

An obvious methodologic consideration in our study is the lack of randomization, with patients allocated to control or intervention through geographic selection. The interventions required close cooperation with primary care and local authorities; this was not feasible with ten social service departments and 25 community health centers. With the lack of randomization, the risk of dissimilarities between the groups at baseline cannot be ignored. The rather extensive baseline measurements showed only subtle differences regarding education level (higher in the intervention group), language barrier (more frequent in the control phase), and occurrence of diabetes (higher in the control group). Together, they could suggest socioeconomic differences, which have previously shown to affect readmissions.$^{38}$ Further, there was a trend suggesting more emergency department visits and fewer general practitioner visits in the control group before the study, possibly indicating lower accessibility to primary care in the boroughs of the control group. In addition, social services and primary care in boroughs $\mathrm{A}$ and $\mathrm{B}$, with a large share of elderly, could be more conscious of and adapted to cognitive symptoms. However, there were no differences between the groups in hospitalizations preceding baseline. Further, we analyzed both groups internally and separately using the Wilcoxon signed-rank test, which demonstrated that health care utilization increased significantly in the control group while remaining unchanged in the intervention group. This result strongly supports our principal assumption that the intervention did in fact contribute to lower readmission rates.

Strengths of the study include its real-life setting in ordinary clinical practice. This is reflected by the rather complex inclusion procedure. Only a third of available patients were included, but the reasons for exclusion were well documented. Further, baseline measurements 
were conducted in a consistent and standardized way and there were very little missing data. All our four interventions were performed in a broad population of general internal medicine patients. General practitioner liaison in particular was targeted specifically to cognitive impairment. However, we chose to perform all interventions in all patients due to the high frequency of cognitive impairment and the fact that two of the interventions (medication review and telephone follow-up) were not targeting cognitive impairment. The material was not considered sufficient for subgroup analyses.

Our results are very promising but further research is needed; the next step should be a larger, randomized study in another location. Such a study could possibly evaluate the interventions separately as well. Unplanned readmissions, drug-related problems, and cognitive impairment are likely to increase in the aging population. With the ongoing reduction of hospital bed capacity, this emphasizes the need for an efficient approach to address these issues. Our results may have several important implications for clinicians and policy-makers because they indicate that managing elderly patients in a multidisciplinary and standardized way could be a cost-efficient method to lower hospital readmissions.

In conclusion, we applied an intervention targeting drugrelated problems, cognitive impairment, and discharge routines in an attempt to reduce readmissions among medical inpatients. Drug-related problems and cognitive impairment were found to be very frequent. Our results suggest that an approach targeting these areas could substantially lower hospital readmissions in this population, albeit further research is needed.

\section{Acknowledgments}

This study was funded by the Swedish Research Council (Vetenskapsrådet \#523-2010-520), the Swedish Brain Power program, the National Swedish Board of Health and Welfare, and the Governmental Funding of Clinical Research within the National Health Services. The sponsors of the study had no role in the study design, data collection, data analysis, data interpretation, or writing of the report. We would like to thank Anna Johansson, Sofia Raccuia, Cecilia Lenander, Annika Dobszai, and Jenny Cappelin for help with acquisition of data.

\section{Disclosure}

LS is a member of an expert group writing a report on "acute care of elderly in hospitals" on behalf of the Swedish Council of Health Technology Assessment (a governmental agency). The other authors declare no conflicts of interest in this work.

\section{References}

1. Jencks SF, Williams MV, Coleman EA. Rehospitalizations among patients in the Medicare fee-for-service program. N Engl J Med. 2009; 360(14):1418-1428.

2. Dharmarajan K, Hsieh AF, Lin Z, et al. Diagnoses and timing of 30-day readmissions after hospitalization for heart failure, acute myocardial infarction, or pneumonia. JAMA. 2013;309(4):355-363.

3. Christensen K, Doblhammer G, Rau R, Vaupel JW. Ageing populations: the challenges ahead. Lancet. 2009;374(9696):1196-1208.

4. Organisation for Economic Co-operation and Development 2012. OECD Health Data: Health care resources. OECD health statistics database. Available from: http://www.oecd-ilibrary.org DOI: 10.1787/ data-00541-en. Accessed February 6, 2013.

5. Graham H, Livesley B. Can readmissions to a geriatric medical unit be prevented? Lancet. 1983;1(8321):404-406.

6. Clarke A. Are readmissions avoidable? BMJ. 1990;301(6761): 1136-1138.

7. van Walraven C, Bennett C, Jennings A, Austin PC, Forster AJ. Proportion of hospital readmissions deemed avoidable: a systematic review. CMAJ. 2011;183(7):E391-E402.

8. Schiotz M, Price M, Frolich A, et al. Something is amiss in Denmark: a comparison of preventable hospitalisations and readmissions for chronic medical conditions in the Danish Healthcare system and Kaiser Permanente. BMC Health Serv Res. 2011;11:347.

9. Fisher ES, Wennberg JE, Stukel TA, Sharp SM. Hospital readmission rates for cohorts of Medicare beneficiaries in Boston and New Haven. N Engl J Med. 1994;331(15):989-995.

10. Westert GP, Lagoe RJ, Keskimaki I, Leyland A, Murphy M. An international study of hospital readmissions and related utilization in Europe and the USA. Health Policy. 2002;61(3):269-278.

11. Fulop G, Strain JJ, Fahs MC, Schmeidler J, Snyder S. A prospective study of the impact of psychiatric comorbidity on length of hospital stays of elderly medical-surgical inpatients. Psychosomatics. 1998;39(3):273-280.

12. Furlanetto LM, da Silva RV, Bueno JR. The impact of psychiatric comorbidity on length of stay of medical inpatients. Gen Hosp Psychiatry. 2003;25(1):14-19.

13. Saravay SM, Pollack S, Steinberg MD, Weinschel B, Habert M. Four-year follow-up of the influence of psychological comorbidity on medical rehospitalization. Am J Psychiatry. 1996;153(3):397-403.

14. Campbell SE, Seymour DG, Primrose WR. A systematic literature review of factors affecting outcome in older medical patients admitted to hospital. Age Ageing. 2004;33(2):110-115.

15. Torisson G, Minthon L, Stavenow L, Londos E. Cognitive impairment is undetected in medical inpatients: a study of mortality and recognition amongst healthcare professionals. BMC Geriatr. 2012;12:47.

16. Phillips CO, Wright SM, Kern DE, Singa RM, Shepperd S, Rubin HR. Comprehensive discharge planning with postdischarge support for older patients with congestive heart failure: a meta-analysis. JAMA. 2004;291(11):1358-1367.

17. Naylor MD, Brooten DA, Campbell RL, Maislin G, McCauley KM, Schwartz JS. Transitional care of older adults hospitalized with heart failure: a randomized, controlled trial. J Am Geriatr Soc. 2004;52(5): 675-684.

18. Naylor MD, Brooten D, Campbell R, et al. Comprehensive discharge planning and home follow-up of hospitalized elders: a randomized clinical trial. JAMA. 1999;281(7):613-620.

19. Rich MW, Beckham V, Wittenberg C, Leven CL, Freedland KE, Carney RM. A multidisciplinary intervention to prevent the readmission of elderly patients with congestive heart failure. $N$ Engl J Med. 1995; 333(18):1190-1195. 
20. Bogardus ST Jr, Desai MM, Williams CS, Leo-Summers L, Acampora D, Inouye SK. The effects of a targeted multicomponent delirium intervention on postdischarge outcomes for hospitalized older adults. Am J Med. 2003;114(5):383-390.

21. Inouye SK, Bogardus ST Jr, Charpentier PA, et al. A multicomponent intervention to prevent delirium in hospitalized older patients. $N \mathrm{Engl}$ J Med. 1999;340(9):669-676.

22. Ruiz B, Garcia M, Aguirre U, Aguirre C. Factors predicting hospital readmissions related to adverse drug reactions. Eur J Clin Pharmacol. 2008;64(7):715-722.

23. Gillespie U, Alassaad A, Henrohn D, et al. A comprehensive pharmacist intervention to reduce morbidity in patients 80 years or older: a randomized controlled trial. Arch Intern Med. 2009;169(9): 894-900

24. Witherington EM, Pirzada OM, Avery AJ. Communication gaps and readmissions to hospital for patients aged 75 years and older: observational study. Qual Saf Health Care. 2008;17(1):71-75.

25. Kripalani S, LeFevre F, Phillips CO, Williams MV, Basaviah P, Baker DW. Deficits in communication and information transfer between hospital-based and primary care physicians: implications for patient safety and continuity of care. JAMA. 2007;297(8):831-841.

26. Charlson M, Szatrowski TP, Peterson J, Gold J. Validation of a combined comorbidity index. J Clin Epidemiol. 1994;47(11):1245-1251.

27. Folstein MF, Folstein SE, McHugh PR. "Mini-mental state". A practical method for grading the cognitive state of patients for the clinician. J Psychiatr Res. 1975;12(3):189-198.

28. Shulman KI. Clock-drawing: is it the ideal cognitive screening test? Int J Geriatr Psychiatry. 2000;15(6):548-561.

29. Gottfries CG, Brane G, Gullberg B, Steen G. A new rating scale for dementia syndromes. Arch Gerontol Geriatr. 1982;1(4):311-330.

30. Hellstrom LM, Bondesson A, Hoglund $\mathrm{P}$, et al. Impact of the Lund Integrated Medicines Management (LIMM) model on medication appropriateness and drug-related hospital revisits. Eur J Clin Pharmacol. 2011;67(7):741-752.
31. Bondesson A, Hellstrom L, Eriksson T, Hoglund P. A structured questionnaire to assess patient compliance and beliefs about medicines taking into account the ordered categorical structure of data. J Eval Clin Pract. 2009;15(4):713-723.

32. Hellstrom LM, Bondesson A, Hoglund P, Eriksson T. Errors in medication history at hospital admission: prevalence and predicting factors. BMC Clin Pharmacol. 2012;12:9.

33. Bondesson A, Eriksson T, Kragh A, Holmdahl L, Midlov P, Hoglund P. In-hospital medication reviews reduce unidentified drugrelated problems. Eur J Clin Pharmacol. 2013;69(3):647-655.

34. The Swedish National Board of Health and Welfare. Indicators of appropriate pharmacological therapy in the elderly [Socialstyrelsen. Indikatorer för god läkemedelsterapi hos äldre]. Article no. 2010-6-29. Available at http://www.socialstyrelsen.se/publikationer2010/2010-6-29. June 2010. Swedish

35. Swedish association of local authorities and regions. Comparison of costs and activity at hospitals 2011 [Sveriges kommuner och landsting. Jämförelse av kostnader och verksamhet på sjukhuskliniker 2011] ISBN: 978-91-7164-902-7. Available at http://webbutik.skl.se/sv/artiklar/ jamforelse-av-kostnader-och-verksamhet-pa-sjukhuskliniker-2011. html. Stockholm, Sweden; 2013. Swedish

36. Emanuel EJ, Emanuel LL. The economics of dying. The illusion of cost savings at the end of life. N Engl J Med. 1994;330(8):540-544.

37. Emanuel EJ. Cost savings at the end of life. What do the data show? JAMA. 1996;275(24):1907-1914.

38. Philbin EF, Dec GW, Jenkins PL, DiSalvo TG. Socioeconomic status as an independent risk factor for hospital readmission for heart failure. Am J Cardiol. 2001;87(12):1367-1371. 


\section{Supplementary materials}

\section{Table S I}

The telephone follow-up (to be done within a week after discharge)

Interview

- How have you been since leaving the hospital?

- Have you encountered any problems after discharge?

$$
\text { - if yes, what kind of problems? }
$$

- Do you know who to turn to with these problems/if you should have a problem?

- Do you want me (the communication nurse) to help you with anything?

- Do you have any questions regarding your medications?

- Do you have appropriate knowledge of your medications?

- Are you taking your medications as prescribed?

- Do you feel safe at home?

- Do you wish to be contacted by the communication nurse again?

\section{After the interview}

Was an action taken by the contact nurse? Yes/no

$$
\text { - if yes, what action? }
$$

How many times has the patient been called?

Has the patient and/or relative contacted the contact nurse?

Total amount of minutes on the phone with this patient:

\begin{tabular}{|c|c|c|}
\hline \multicolumn{3}{|c|}{ GP liaison - algorithm for recommendations } \\
\hline \multicolumn{3}{|c|}{ Clock-Drawing Test abnormal (Shulman 0-3) } \\
\hline Age (years) & MMSE & Recommendation to GP \\
\hline \multirow[t]{3}{*}{$60-80$} & $27-30$ & $\begin{array}{l}\text { Renewed evaluation and cognitive tests } \\
\text { within I year }\end{array}$ \\
\hline & $24-26$ & $\begin{array}{l}\text { Renewed evaluation and cognitive tests } \\
\text { within } 6 \text { months }\end{array}$ \\
\hline & $0-23$ & $\begin{array}{l}\text { Renewed evaluation and cognitive tests } \\
\text { promptly }\end{array}$ \\
\hline \multirow[t]{3}{*}{$80+$} & $26-30$ & $\begin{array}{l}\text { Renewed evaluation and cognitive tests } \\
\text { within I year }\end{array}$ \\
\hline & $23-25$ & $\begin{array}{l}\text { Renewed evaluation and cognitive tests } \\
\text { within } 6 \text { months }\end{array}$ \\
\hline & $0-22$ & $\begin{array}{l}\text { Renewed evaluation and cognitive tests } \\
\text { promptly }\end{array}$ \\
\hline \multicolumn{3}{|c|}{ Clock-Drawing Test normal (Shulman 4-5) } \\
\hline Age & MMSE & Recommendation to GP \\
\hline \multirow[t]{4}{*}{ All } & $27-30$ & $\begin{array}{l}\text { No further action needed at the } \\
\text { moment }\end{array}$ \\
\hline & $25-26$ & $\begin{array}{l}\text { Renewed evaluation and cognitive tests } \\
\text { within I year }\end{array}$ \\
\hline & $22-24$ & $\begin{array}{l}\text { Renewed evaluation and cognitive tests } \\
\text { within } 6 \text { months }\end{array}$ \\
\hline & $0-21$ & $\begin{array}{l}\text { Renewed evaluation and cognitive tests } \\
\text { promptly }\end{array}$ \\
\hline
\end{tabular}

\section{Table S2}

Abbreviations: GP, general practitioner; MMSE, Mini-Mental State Examination, scored from 0 (worst) to 30 (best).
Clinical Interventions in Aging

\section{Publish your work in this journal}

Clinical Interventions in Aging is an international, peer-reviewed journal focusing on evidence-based reports on the value or lack thereof of treatments intended to prevent or delay the onset of maladaptive correlates of aging in human beings. This journal is indexed on PubMed Central, MedLine, the American Chemical Society's 'Chemical Abstracts

\section{Dovepress}

Service' (CAS), Scopus and the Elsevier Bibliographic databases. The manuscript management system is completely online and includes a very quick and fair peer-review system, which is all easy to use. Visit $\mathrm{http}: / /$ www.dovepress.com/testimonials.php to read real quotes from published authors. 